Review of Educational Research

Spring 1975, Vol. 45, No. 2, Pp. 231-246

\title{
The Relationship of Counselor Characteristics and Counseling Effectiveness
}

\author{
Wayne Rowe \\ University of Oklahoma
}

Harry B. Murphy

University of Oklahoma

Robert A. De Csipkes

National Naval Medical Center

Studies of counselor characteristics have occupied the attention of counselor educators since the field came of age in the 1950 's. The assumption that has worked to maintain this interest over the years is that certain personality variables are associated with, or are the cause of, the different degrees of counselor competence that seem to exist. In addition, many persons engaged in the training of counselors have found that some students appear to adapt readily to the counseling role, whereas others seem to be confused, in conflict, and generally illsuited to the educator's expectations. Therefore, a commonly held assumption and personal observation, which seem to support that assumption, have both contributed to sustaining a point of view that reasonably ought to be verified, altered, or abandoned on the merits of the research evidence. 
Two decades ago Cottle (1953) reported the research on this topic to be wanting because of the subjectivity, circularity, and uncontrolled sources of data contamination and because the characteristics that were involved lack relevance theoretically. More recently, Patterson (1967) has commented that studies in this area suffer from a number of deficiencies, including the use of vague criteria and the possibility that "discovered" characteristics may be an artifact of the criteria employed by the raters or judges. Still, similar research continues unabated with little concern shown for the fact that few emerging consistencies seem to accrue.

This paper examines the relationship between counselor characteristics and counseling effectiveness by reviewing the research reported since 1960 , by commenting on various approaches, and by attempting to identify the conclusions that may reasonably be supported by the available evidence.

\section{Criterion Problems}

A recurring problem in research on this topic has been the stumbling block presented by the criteria chosen to measure effectiveness. An early study (Stefflre, King, \& Leafgren, 1962) simply had the counselor trainees nominate each other as effective counselors and compared those most chosen with those least chosen. Frequently, however, the effectiveness of a counselor is determined by the evaluation of a supervisor or faculty member, and these data are sifted for some relationship with the dependent measures that are chosen. Some studies are found in which a global judgment of "good" counseling is arrived at by undetermined means; others determine effectiveness with the aid of rating scales, check lists, or some device that tends to structure the process. Far less research has been conducted in which some measure of counseling outcome or performance has been related to significant personal variables of the counselor. Each of these approaches will be discussed in turn.

\section{Effectiveness Determined by Global Judgment}

Numerous studies have been performed that utilize global ratings of effectiveness as the sole criterion measure.

Kazienko and Neidt (1962) administered the Bennett Polydiagnostic Index to subjects who had been designated as either "good" or "poor" counselors by their supervisors. Their analysis generated a list of adjectives describing the "good" counselor along the parameters of self-concept, motivation, value patterns, and feeling about other people. From this they described a composite personality of the "good" counselor. 
Wicas and Mahan (1966) compared NDEA institute student responses to the Ways of Life Test, a forced-choice adjective check list, and the Structured Objective Rorschach (SORT) with instructor ratings. The results obtained from the Ways of Life indicated that high-rated counselors described themselves as having more concern for others, more concern with improving society and with maintaining appropriate controls over self and others. On the SORT, high-rated counselors seemed more conforming and less persistent, whereas those rated low were described as likely to be more resistant to change but less anxious than the high-rated counselors. Again, adjectives which the researchers believed to be characteristic of the "good" counselor were compiled. As is usually the case in this kind of research, no startling selfdescriptors emerged, thus attesting once more to the power of unrestrained circularity.

Blocher (1963) expanded on the global criterion method in an attempt to predict success in counselor education. He compared peer rankings, NDEA comprehensive examinations, school counselor scores on the Kuder Personal Preference Record, and course grades with the criterion measure of combined faculty rankings of who would probably perform well as a school counselor. Using a multiple regression analysis of the data, he found that both peer rankings and the Kuder score were useful indicators of predicted counselor success.

Tolerance of ambiguity was investigated in studies conducted by McDaniel (1967) and by Gruberg (1969). McDaniel compared subjects' scores on Budner's Scale of Tolerance of Ambiguity, the Minnesota Test of Creative Thinking, and the IntellectualPragmaticism Scale with supervisor ratings of counselor effectiveness. The results revealed a significant correlation only between tolerance of ambiguity and counselor rating. In the Gruberg study, tolerance of ambiguity, as measured by the complexity scale of the Omnibus Personality Inventory, was compared with both orientation to counseling and rated effectiveness of counseling responses in taped sessions. A significant relationship was found to exist between measured tolerance and rated effectiveness of responses. Also, high tolerance counselors tended to be more client-centered, whereas the low tolerance counselors were more directive.

McClain (1968) compared supervisor ratings of counseling practicum students with their scores on the Sixteen Personality Factor Questionnaire (16PF). Specific scales of the 16PF were found to interact strongly with the sex of the counselor. Desirable traits for males reflected masculine characteristics, and high-rated females were found to be more feminine.

Combs and Soper (1963) had trained raters categorize the perceptual style of NDEA institute members as inferred from 
descriptions of four "human relations" incidents. Ratings on four dimensions were ranked and compared with the composite effectiveness rank assigned to the counselors by their instructors. The obtained data indicated significant correlations for all aspects of perceptual organization and ranked competence.

Little comment can be made in regard to the above studies. The lack of clarity concerning the basis for determining "effectiveness" makes replication fruitless and has brought forth the characterization of such work as popular, though unproductive (Whiteley, 1969).

\section{Effectiveness Assessed by Scales and Other Devices}

Other studies have attempted to avoid or to minimize such deficiencies by invoking one or both of the following strategies. Counseling competence may be rated on some limited dimension such as empathy or communication effectiveness. The other tack, often taken concurrently, is the use of some formal rating device in order to specify, to some degree, what is being evaluated.

The relationship between various counselor personality characteristics and ratings of empathy was investigated in studies conducted by Bergin and Solomon (1963) and by Passons and Olsen (1969). Bergin and Solomon compared subjects' scores on the Edwards Personal Preference Schedule (EPPS), Graduate Record Examination (GRE), and grade-point average (GPA) with ratings of empathy made from taped counseling sessions. Analysis of the data indicated a slight positive correlation between the EPPS scales of Dominance and Change and the criterion of effectiveness. Furthermore, a slight negative correlation was found to exist for the EPPS scales of Anxiety, Depression, Intraception, and Order. No correlation was found for either the GRE scores or GPA. In the Passons and Olsen study, numerous characteristics of 30 NDEA institute students were compared with practicum supervisors' ratings of empathic sensitivity and trained judges' ratings of empathy expressed to a filmed client. The resulting data indicated that the peer ratings of ability to sense feelings and the willingness to communicate in the realm of feelings were significantly correlated with the supervisor ratings of empathic sensitivity, and that the cognitive flexibility scores were correlated with the judges' ratings. However, the validity of the criterion ratings must be questioned since there was no relationship between empathic levels expressed to practicum clients and filmed clients, as measured.

Another study that investigated cognitive flexibility as a possible characteristic of effective counselors was conducted by Whiteley, Sprinthall, Mosher, and Donagly (1967). Cognitive flexibility, as measured by the Rorschach, the Thematic Appercep- 
tion Test (TAT), the Personal Differentiation Test (PDT), "critical situation" case studies, and simulated counseling cases, was compared with supervision ratings on the Counselor Rating Blank. The findings indicated that cognitive flexibility, as measured by the projective tests and the case studies, did correlate significantly with the supervisors' ratings. No correlation was found to exist between subjects' scores on either the MAT or GRE and the criterion. It should be noted that the Counselor Rating Blank does not measure effectiveness per se, but rather flexible versus rigid counseling style. As yet, there is little evidence leading one to relate high scores on the Counselor Rating Blank with effective outcomes in counseling.

The characteristics of open-mindedness were of main concern in the studies by Russo, Kelz, and Hudson (1964) and by Milliken and Paterson (1967). The former study compared subjects' scores on the Rokeach Dogmatism Scale (RDS) with judges' ratings of counseling effectiveness, utilizing the Interview Counselor Performance Rating Scale devised by Kelz. The resulting data indicated that a high positive correlation existed. Milliken and Paterson found contrary results. In this later study, 30 NDEA institute subjects were administered the Bogardus Ethnic Distance Scale and the RDS. Scores were compared with both coached clients' and supervisors' ratings of effectiveness, using the Counselor Effectiveness Scale (CES). The analysis of the resulting data did not support the hypothesized relationship between scores on either prejudice or dogmatism and the criterion of effectiveness.

Brams (1961) used effectiveness of communication as the criterion measure. In this study, numerous personality characteristics, as measured by the Minnesota Multiphasic Personality Inventory (MMPI), the Taylor Manifest Anxiety Scale (MAS), the Bills Index of Adjustment and Values (IAV), and the Berkeley Public Opinion Questionnaire (POQ), were compared with subject scores on the Communication Rating Scale (CRS). Each of the 27 subjects was rated independently by at least two practicum supervisors. Findings indicated that only one personality characteristic, Tolerance of Ambiguity on the POQ, reached significance in correlation with the CRS. Another study concerned with counselor communication was conducted by Freedman, Antenen, and Lister (1967). California Psychological Inventory (CPI) and Guilford-Zimmerman Temperament Survey (GZTS) responses were compared with subjects' verbal response patterns on a modified Porter Interview Analysis Scale (PIAS). The 37 subjects were rated by judges on their verbal responses following a 15-minute role play interview with a coached client. The resulting data revealed a positive relationship between certain counselor personality characteristics and verbal re- 
sponse patterns. However, which of the verbal response patterns that were utilized are more facilitative of personal growth or behavioral change in the counselee remains unknown.

Several studies have investigated the relationship between subjects' scores on the Sixteen Personality Factor Questionnaire (16PF) and scale ratings of counseling effectiveness. Donnan, Harlan, and Thompson (1969) compared 16PF scores with selected interview behavior ratings as judged by naive counselees using the Relationship Inventory (RI). An analysis of the resulting data indicated that Factor A (outgoing, warm-hearted) on the 16PF correlated significantly with unconditional positive regard. Also, Factor C (emotionally stable) correlated positively with congruence and Factor $\mathrm{H}$ (venturesome) with trust. Furthermore, Factor A was found to be correlated positively with total relationship ratings. The validity of client assessment of counselor performance, however, is uncertain (Bishop, 1971; Brown \& Cannaday, 1969; McIlvaine, 1973). A similar study Wittmer \& Lister, 1971) compared 53 subjects' scores on the $16 \mathrm{PF}$ and GRE with supervisors' ratings on the Counselor Evaluation Rating Scale (CERS). While the scores on the GRE were unrelated to the CERS, a significant correlation (.41) was found between supervisor ratings on this scale and an index of predicted counseling effectiveness derived from the $16 \mathrm{PF}$ specification equation (McClain, 1968). Although, to the best of our knowledge, this combination of predictors from the $16 \mathrm{PF}$ has not been crossvalidated, this has not deterred its use in subsequent studies reported below (Shelton, 1973; Wehr \& Wittmer, 1973). Myrick, Kelly, and Wittmer (1972) compared the $16 \mathrm{PF}$ scores of 40 student counselors who had been rated as either effective or ineffective by supervisors using the CERS. Four of the $16 \mathrm{PF}$ factors $(\mathrm{A}, \mathrm{E}, \mathrm{H}$, I) were found to correlate significantly with the supervisors' ratings. These findings correspond somewhat with those of Donnan, Harlan, and Thompson reported (1969) above.

Wehr and Wittmer (1973) compared professional and paraprofessional counselor trainees using the $16 \mathrm{PF}$ and found significant differences on eight of the 16 dimensions (B, C, G, I, L, M, O, and $Q_{4}$ ). They also found that more professional than paraprofessional trainees were predicted to be effective counselors using the $16 \mathrm{PF}$ specification equation. However, neither this study nor Myrick, Kelly, and Wittmer (1972) found the substantial discrepancies in the traits of effective male and female counselors reported by McClain (1968).

Shelton (1973) used a composite client-rating on the Counseling Evaluation Inventory (CEI) as the criterion of counselor effectiveness. A comparison of the $16 \mathrm{PF}$ scores of those rated more effective with those rated less effective produced the stereotypic masculine and feminine profiles earlier noted by McClain (1968) 
for the effective male and female subjects. In addition, Shelton reported a high correlation (.87) between the criterion and the $16 \mathrm{PF}$ specification equation.

Myrick, Kelly, and Wittmer (1972) and Shelton (1973) call for the use of the $16 \mathrm{PF}$ as an instrument to be used in the selection of individuals as counselor trainees. This suggestion seems premature for several reasons. Considerable variation exists in the findings reported in the various $16 \mathrm{PF}$ studies, particularly in the desirable attributes associated with male and female counselors. What consensus that does exist has been demonstrated using group data. Therefore, little confidence can be placed on individual prediction. In addition, it should be pointed out that the $16 \mathrm{PF}$ specification equation was originally derived from supervisor ratings.

Several points can be made about the studies reported in this section:

1. Most variables investigated were not significantly related to the criterion employed.

2. Where a variable was found to be significant once but was investigated more than once, contrary results were often shown.

3. Although efforts were made to define counseling effectiveness more precisely, a clear relationship is lacking between the measures employed and counselors' ability to help clients with their problems.

\section{Effectiveness Assessed by Multiple Criteria}

Bernos (1966) and McGreevy (1967) investigated standardized instruments commonly used as predictors of success in counseling and guidance training programs. Bernos compared 57 counselor selection criteria variables, drawn from the MMPI, GZTS, MAT, EPPS, etc., with eight criteria of counselor candidate's success, including a composite rating by institute staff members and GPA. Data were collected from 447 participants of NDEA counseling institutes. It was reported that 15 of the factors accounted for all the variance in the male sample and 16 factors in the female sample. However, more significant here, none of the factors were found to be significant predictors, and it was concluded, simply, that tests were poor predictors of counselor trainee success. McGreevy, using 86 counseling candidates enrolled in NDEA counseling and guidance institutes, conducted a factor analysis of several measures commonly used to select counselor candidates. Fourteen factors were extracted, and data for each factor were compared with three types of evaluative criteria: (a) NDEA institute comprehensive exam scores, (b) 
institute grade-point average, and (c) institute faculty ratings. Results indicated that faculty ratings were not related to any other selection or evaluation data. The data did support the use of the MAT for identifying academically able candidates.

Jansen, Robb, and Bonk (1970) employed a composite measure of counseling competence that included knowledge of theories and techniques, ability to use tests, and ability to counsel effectively as determined by analysis of taped interviews. Subjects who were rated in the top quarter and in the bottom quarter (each $\mathrm{N}=17$ ) were compared on several dimensions. The highrated group was found to score higher on two measures of scholastic aptitude, GPA, practicum grade, three of ten scales on the GZTS, and on the Minnesota Teacher Attitude Inventory (MTAI).

Other investigators, notably Graff (1970) and Eberlein and Park (1971), have compared the data from standardized instruments of self-disclosure or self-concept with ratings of counselor effectiveness. Graff's study compared scores on Jourard's SelfDisclosure Inventory (SDI) with client ratings of effectiveness using the Counselor Evaluation Inventory (CEI) and practicum supervisor ratings on a seven-point scale designed by Sprinthall. Data were obtained from 41 graduate students enrolled in practicum. Results indicated a significant correlation with the criterion scores of effectiveness. Eberlein and Park were concerned with the relationship between self-concept/ideal-self-concept (S-I) congruence, as measured by the interpersonal check list, and trainee performance as indicated by supervisor ratings and final grades. No evidence was found to support a linear relationship, although a curvilinear trend was noted, i.e., moderate S-I discrepancies received higher ratings than either low or high S-I discrepancies.

Demos and Zuwaylif (1966) studied the characteristics of effective high school counselors. The counselors were rated as high (N $=15)$ or low $(\mathrm{N}=11)$ effective on rating scales of counseling sessions, peer ratings after critiquing tapes, observations through closed circuit TV and one-way vision screens, and client ratings of counselor. Counselor responses to the AllportVernon-Lindsey Study of Values, the Kuder Preference Record (Personal), and the EPPS were then compared. Although scores on the Study of Values and the Kuder Preference Record did not discriminate between the high- and low-rated counselors, five of the sixteen scales on the EPPS discriminated between the groups. The authors suggest that this instrument may be sensitive to some pertinent counselor personality characteristics. However, when these results are combined with those of Stefflre, King and Leafgren (1962) and of Bergin and Solomon (1963), it is found that nine of the 16 EPPS scales have been nominated for 
significance, yet only two were cited twice (negative correlations for both aggression and abasement).

Johnson, Shertzer, Linden, and Stone (1967) examined the relationships between a battery of standard tests, self-ratings, peer-ratings, supervision ratings, and GPA for 99 counselor candidates. Counseling effectiveness was estimated by counselees, peers, and supervisors. The data revealed only a few relationships to criteria. For the male sample, the architect score of the SVIB and the well-being scale of the CPI were positive predictors. For the female sample, the schizophrenia on the MMPI, the friendliness scale of the CPI, and the dentist score of the SVIB were negatively associated with effectiveness. Their concluding statement, which could be generalized to all the studies discussed here, was that an important question was left unresolved-what constitutes effective counseling?

When multiple criteria, such as reported, are used to estimate counselor effectiveness, the kinds of problems referred to above are likely to remain, and other sources of concern come into focus. For instance, since the criteria often seem to measure rather independent elements, they should not properly be combined. However, if the criteria are treated separately, given the typical forms of analysis employed, the chance occurrence of significance findings will increase. A particularly disturbing aspect of this approach is the suspicion that the results obtained are in part a function of the choice of criteria.

\section{Effectiveness Assessed by External Criteria}

In an effort to avoid the criteria problems encountered in the previously discussed studies, some researchers have attempted to use a more objective criterion measure.

Dispenzieri and Balinsky (1963) investigated the relationship between the ability to acquire interviewing skills and the characteristics of authoritarianism and manifest anxiety. In the study, 50 students were administered the California Authoritarian Scale and the Taylor Manifest Anxiety Scale. The criterion measure employed was the difference score between preinstruction and postinstruction administrations of the Counseling Interviewing Test developed by Porter. No relationships were found to exist between either authoritarianism or manifest anxiety and the criterion measure.

In another study, Gonyea (1963) compared quality of the therapeutic relationship to effectiveness of counseling. For each of the eight counselor-intern subjects, the quality of the therapeutic relationship was measured by counseling supervisors using Fiedler's composite Q-sort of the Ideal Therapeutic Relationship. The criterion of effectiveness was measured by a 
precounseling and postcounseling administration of the SelfDescription Form (SD) for 208 clients over a three-year period. An increased score on the SD was felt to reflect improvement or more adequate adjustment. An analysis of the data indicated that, although effectiveness and quality of therapeutic relationship were both positively correlated with therapist experience, they were not correlated with each other.

Jackson and Thompson (1971) compared counselor effectiveness with measures of cognitive flexibility, tolerance of ambiguity, and attitudes toward self, most people, most clients, and counseling. The independent variables were obtained by a case episode approach to measure cognitive flexibility, the Hanson modification of Budner's Intolerance-Tolerance for Ambiguity Scale and the Osgood Semantic Differential. The 73 school counselor subjects were rated on effectiveness by evidence of client movement toward self-understanding, self-acceptance, skills in satisfying needs, decision-making skills, and specific goal attainment. The only significant finding was that effective counselors were more positive in counseling-related attitudes than were those who were least effective. However, it is suggested here that these positive attitudes may be a consequence of, rather than the cause for, being effective.

The measure of counseling success employed by Trotter and her colleagues (1971) was the percentage of cases closed as successful that were assigned to the rehabilitation counselors involved in the study. The counselors were administered the Personal Orientation Inventory (POI), a personality device based largely on the construct of self-actualization, and the predictive utility of each scale was examined. Results indicated that neither major scale nor any of the ten subscales, each a component of the larger concept, were significantly related to counselor success. Nevertheless, it was discovered that the shorter of the main scales, in combination with two of the subscales, resulted in a multiple predictor of .55. A severe limitation, however, exists due to the brevity and item overlap of the scales and to the absence of cross-validation. Unfortunately, since the labeled traits involved (time competence, capacity for intimate contact, and selfacceptance) do not correspond with any clear subset of selfactualization, without closer analysis it cannot be determined if we have effect or artifact.

Nevertheless, the POI is a particularly interesting instrument for use in the investigation of personality attributes related to counseling success. Whereas the use of other devices affords a rather eclectic, if not haphazard, approach to psychological dimensions of interest, the POI is based on a model of adjustment that is consistent with humanistically flavored theories and is thought to be necessary if successful counseling is to be offered. 
Foulds (1969a, 1969b) used the POI in conjunction with an indirect measure of counseling outcome, performance on the rating scales developed by Carkhuff (1969). To consider such performance an estimate of expected results may be justified on the basis that evidence points to a positive relationship between rated performance and subsequent counseling outcome (Carkhuff, 1969). Trained judges, using the scales for empathy, regard, and genuineness, rated the counseling of 30 practicum students who also completed the POI. It was found that various subscales of the POI were significantly correlated with the counselors' rated performance for empathy, genuineness, and a composite score for all three dimensions. It was concluded that particular personality correlates of the ability to perform effectively in counseling had been identified. These results could not, however, be confirmed (Rowe \& Winborn, 1973). The complete correlational matrix was found to yield one significant figure, attributed to chance, when replication was attempted (Winborn $\&$ Rowe, 1972). Foulds (1971) also investigated the relationship of dogmatism to rated performance on empathy, regard, and genuineness. In this case a nonsignificant result was obtained.

The studies cited above have an advantage in relating more objective measures of counseling effectiveness to personality dimensions of concern. However, the price that was exacted may be reflected in the lack of positive findings.

\section{Discussion}

Given the rather sizeable effort that has been invested in this area, the results may be viewed as generally disappointing, often contradictory, and only tentative. In addition to the dearth of positive leads, several dissonant statements have appeared. A multivariate analysis, for instance, by Moos and MacIntosh (1970) indicates that the tendency to be empathic does not appear to be the result of a "trait," but is more situationally determined. Knowles and Barr (1968), noting the emphasis on ideal subjective traits of counselors, have pointed to studies of effective people that demonstrate the importance of objective traits and attitudes as well. Moreover, characteristics identified with successful college counselors were found to be those related to interpersonal skills rather than essential attributes of the counselor as an individual (Schoenberg, 1971).

Perhaps one reason for the persistence of this type of research is that the assumptions are shared by many counseling theories. In most dynamic and experiential humanistic approaches, the locus of concern is upon the inferred, internal states and introspective (consequently unobservable) characteristics of counselors and their clients rather than upon the external, observ- 
able behavior that individuals demonstrate in their environments. Theory ought to provide direction for research, but when continued investigation yields little in return, reassessment of assumptins and/or procedures should be in order.

As a result of the consistent lack of success associated with the identification of preferred counselor characteristics, it has been suggested that the pursuit of specific traits be abandoned in favor of investigations concerned with higher order variables (Sprinthall, Whiteley, \& Mosher, 1966; Doyle \& Conklin, 1970). Although Allen (1967) has followed this tack with some success, the long-term fruitfulness of this approach seems limited because of the vagueness of the analysis that results and the assumptions that are shared with the research that is repudiated. A more satisfactory resolution would seem to be outlined by Mosher (1967) who has called for a change in emphasis from what the counselor is to what he can perform. If necessary counseling skills can be identified, it would seem purposeless to attempt to locate characteristics that have less than a chance association with the behaviors of interest. Instead, the focus of research would shift from the personality of the counselor to particular behaviors, skills, or interactions and their relationship to counseling outcome.

Initial efforts at associating particular counselor behaviors with counseling outcome have yielded rather optimistic results. Carkhuff and his associates have identified and operationally defined a number of behaviors that appear to be facilitative in the counseling relationship and positively related to subsequent treatment success. For instance, clients of high-facilitative counselors engaged in significantly more self-exploration than clients of low-facilitative counselors (Banks, Berenson, \& Carkhuff, 1966). Furthermore, numerous investigations (summarized by Carkhuff, 1972) have succeeded in demonstrating the significant influence of high counselor facilitation on other, more direct, indices of counseling outcome (information-seeking behavior, ward behavior, rated improvement, work level, employment). It is Carkhuff's view that the high-facilitator is a person who possesses a large repertoire of skills, rather than one who represents certain abstract personality traits. Carkhuff's major emphasis has been the development of training programs aimed at teaching these skills systematically.

Any mention of a skills approach to counselor education would not be complete without some elaboration on Ivey's microcounseling approach (Ivey, 1971). This training approach teaches interviewer behaviors that can be behaviorally defined and described in a written manual, as well as modeled on videotape. Several studies (Boyd, 1973; Miller, Morrill, \& Uhlemann, 1970; Moreland, Ivey, \& Phillips, 1973) have demonstrated the effec- 
tiveness of the microcounseling technique in teaching numerous interviewer skills (i.e., attending behavior, minimal activity responses, reflection of feelings, etc.). Those changes brought about by microcounseling have been shown to result in specific positive changes in client interview behavior (Ivey, 1971). Numerous nonverbal communication modalities (proximics, eye behavior, body position, and facial gesture) have been subjected to systematic research within the counseling context (Hackney, 1974; Hasse, 1970; Hasse \& Tepper, 1972). Initial findings seem to support a model such as that proposed by Ivey, Normington, Miller, Morrill, and Hasse (1968). Others have proposed various approaches that emphasize a variety of specific counselor behaviors (Danish \& Hauer, 1973; Hosford \& de Visser, 1974; Kagan, 1972; Winborn, 1973; Cormier, Note 1).

The studies referred to above can be considered neither exhaustive nor representative of the work that has focused on particular skills or behaviors associated with effective counseling. Continued research is needed in order to define more precisely the performance parameters that affect counseling outcome. Hopefully, investigations of this sort will generate information of greater utility than has been yielded by the continued quest for the ideal counselor personality type.

\section{Reference Note}

1. Cormier, L. S. Developing and evaluating self-instructional strategies for human services training. Symposium presented at the meeting of the American Educational Research Association, Washington, D.C., 1975.

\section{References}

Allen, T. W. Effectiveness of counselor trainees as a function of psychological openness. Journal of Counseling Psychology, 1967, 14, 35-40.

Banks, G., Berenson, B. G., \& Carkhuff, R. R. The effects of counselor race and training upon the counseling process with Negro clients in initial interviews. Journal of Clinical Psychology, 1966, 13, 441-446.

Bergin, A., \& Solomon, S. Personality and performance correlates of emphatic understanding in psychotherapy. American Psychologist, 1963, 18, 393.

Bernos, E. C. Factors related to success in fifteen NDEA counseling and guidance institutes. Counselor Education and Supervision, 1966, 5, 94-104.

Bishop, J. B. Another look at counselor, client, and supervisor ratings of counselor effectiveness. Counselor Education and Supervision, 1971, 10, 319-323.

Blocher, D. H. A multiple regression approach to predicting success in a counselor education program. Counselor Education and Supervision, 1963, 3, 19-22.

Boyd, J. D. Microcounseling for a counseling-like verbal response set: Differential effects of two micro models and two methods of counseling supervision. Journal of Counseling Psychology, 1973, 20, 97-98.

Brams, J. M. Counselor characteristics and effective communication in counseling. Journal of Counseling Psychology, 1961, 8, 25-30.

Brown, D., \& Cannaday, M. Counselor, counselee, and supervisor ratings of counselor effectiveness. Counselor Education Supervisor, 1969, 8, 113-118. 
Carkhuff, R. R. Helping and human relations. New York: Holt, Rinehart and Winston, 1969.

Carkhuff, R. R. Some reflections on helping and human resource development models. The Counseling Psychologist, 1972, 3, 79-87.

Combs, A. W., \& Soper, D. W. The perceptual organization of effective counselors. Journal of Counseling Psychology, 1963, 10, 222-226.

Cottle, W. C. Personal characteristics of counselors. Personnel and Guidance Journal, 1953, 31, 445-450.

Danish, S. J., \& Hauer, A. L. Helping skills: A basic training program. New York: Behavioral Publications, 1973.

Demos, G. D., \& Zuwaylif, F. H. Characteristics of effective counselors. Counselor Education and Supervision, 1966, 5, 163-165.

Dispenzieri, A., \& Balinsky, B. Relationship between the ability to acquire interviewing skills and authoritarianism and manifest anxiety. Personnel and Guidance Journal, 1963, 42, 40-42.

Donnan, H. H., Harlan, G. E., \& Thompson, S. A. Counselor personality and level of functioning as perceived by counselees. Journal of Counseling Psychology, $1969,16,482-485$.

Doyle, W. L., \& Conklin, R. C. Counselor effectiveness: A changing emphasis. Canadian Counselor, 1970, 4, 269-276.

Eberlein, L., \& Park, J. Self-concept/ideal-self-concept congruence and rated effectiveness of counselor trainees. Counselor Education and Supervision, $1971,10,126-132$.

Foulds, M. L. Self-actualization and level of counselor interpersonal functioning. Journal of Humanistic Psychology, 1969, 9, 87-92.

Foulds, M. L. Self-actualization and the communication of facilitative conditions during counseling. Journal of Counseling Psychology, 1969, 16, 132-136.

Foulds, M. L. Dogmatism and the ability to communicate facilitative conditions during counseling. Counselor Education and Supervision, 1971, 11, 110-114.

Freedman, S. A., Antenen, W. W., \& Lister, J. L. Counselor behavior and personality characteristics. Counselor Education and Supervision, 1967, 7, 26-30.

Gonyea, G. G. The 'ideal therapeutic relationship' and counseling outcome. Journal of Clinical Psychology, 1963, 19, 481-487.

Graff, R. W. The relationship of counselor self-disclosure to counselor effectiveness. Journal of Experimental Education, 1970, 38, 19-22.

Gruberg, R. A significant counselor personality characteristic: Tolerance of ambiguity. Counselor Education and Supervision, 1969, 8, 119-124.

Hackney ,H. Facial gestures and subject expression of feelings. Journal of Counseling Psychology, 1974, 21, 173-178.

Hasse, R. Relationship of sex and instructional set to the regulation of interpersonal interaction distance in a counseling analogue. Journal of Counseling Psychology, 1970, 17, 233-236.

Hasse, R., \& Tepper, D. T. Nonverbal components of empathic communication. Journal of Counseling Psychology, 1972, 19, 417-424.

Hosford, R. E., \& de Visser, L. A. Behavioral approaches to counseling. Washington: American Personnel and Guidance Association, 1974.

Ivey, A. Microcounseling: Innovations in interviewing training. Springfield, Ill.: C. C. Thomas, 1971 .

Ivey, A. E., Normington, C. J., Miller, C. D., Morrill, W. H., \& Hasse, R. F. Microcounseling and attending behavior: An approach to prepracticum counselor training. Journal of Counseling Psychology, 1968, 15, 1-12. (Monograph Supplement, No. 5, Pt. 2)

Jackson, M., \& Thompson, L. Effective counselor: Characteristics and attitudes. Journal of Counseling Psychology, 1971, 18, 249-254. 
Jansen, D. G., Robb, G. P., \& Bonk, E. C. Characteristics of high-rated and low-rated master's degree candidates in counseling and guidance. Counselor Education and Supervision, 1970, 9, 162-169.

Johnson, D., Shertzer, B., Linden, J. E., \& Stone, S. C. The relationship of counselor candidate characteristics and counseling effectiveness. Counselor Education and Supervision, 1967, 6, 297-304.

Kagan, N. Influencing human interaction. E. Lansing, Mich.: Michigan State University, College of Education, 1972.

Kazienko, L. W., \& Neidt, C. O. Self-descriptions of good and poor counselor trainees. Counselor Education and Supervision, 1962, 1, 106-123.

Knowles, R. T., \& Barr, D. J. Pseudo-subjectivity in counseling. Personnel and Guidance Journal, 1968, 46, 572-579.

McClain, E. W. Sixteen personality factor questionnaire scores and success in counseling. Journal of Counseling Psychology, 1968, 15, 492-496.

McDaniel, S. W. Counselor selection: An evaluation of instruments. Counselor Education and Supervision, 1967, 6, 142-144.

McGreevy, C. P. Factor analysis of measures used in the selection and evaluation of counselor education candidates. Journal of Counseling Psychology, 1967, 14, 51-56.

McIlvaine, J. F. Coached clients as raters of counseling effectiveness. Counselor Education and Supervision, 1973, 12, 123-129.

Miller, C. D., Morrill, W., \& Uhlemann, M. Microcounseling: An experimental study of pre-practicum training in communicating test results. Counselor Education and Supervision, 1970, 9, 171-177.

Milliken, R. L., \& Paterson, J. J. Relationship of dogmatism and prejudice to counseling effectiveness. Counselor Education and Supervision, 1967, 6, 125-129.

Moos, R. H., \& MacIntosh, S. Multivariate study of the patient therapist system: A replication and extension. Journal of Consulting and Clinical Psychology, 1970, 35, 298-306.

Moreland, J. R., Ivey, A. E., \& Phillips, J. S. An evaluation of microcounseling as an interviewer training tool. Journal of Consulting and Clinical Psychology, $1973,41,294-300$.

Mosher, R. L. Teacher effectiveness research: Implications for research on counselor selection and effectiveness. In J. M. Whiteley (Ed.), Research in Counseling. Columbus, Ohio: Charles E. Merrill, 1967.

Myrick, R. D., Kelly, F. D., \& Wittmer, J. The Sixteen Personality Factor Questionnaire as a predictor of counselor effectiveness. Counselor Education and Supervision, 1972,11,293-301.

Passons, W. R., \& Olsen, L. C. Relationship of counselor characteristics and empathic sensitivity. Journal of Counseling Psychology, 1969, 16, 440-445.

Patterson, C. H. The selection of counselors. In J. M. Whiteley (Ed.), Research in Counseling. Columbus, Ohio: Charles E. Merrill, 1967.

Rowe, W., \& Winborn, B. B. Self-actualization and counselor interpersonal functioning: A replication. Journal of Humanistic Psychology, 1973, 13, 79-84.

Russo, J. R., Kelz, J. W., \& Hudson, G. R. Are good counselors open-minded? Counselor Education and Supervision, 1964, 3, 74-77.

Schoenberg, B. M. Personal characteristics of the successful counselor. Canadian Counselor, 1971, 5, 251-256.

Shelton, J. E. Counselor characteristics and effectiveness in serving economically disadvantaged and advantaged males. Counselor Education and Supervision, 1973, 13, 129-136.

Sprinthall, N. A., Whiteley, J. M., \& Mosher, R. L. Cognitive flexibility: A focus for research on counselor effectiveness. Counselor Education and Supervision, 1966, 5, 188-197. 
Stefflre, B., King, P., \& Leafgren, F. Characteristics of counselors judged effective by their peers. Journal of Counseling Psychology, 1962, 9, 334-340.

Trotter, A. B., Uhlig, G. E., \& Fargo, G. E. Self-actualization as a predictor of rehabilitation counselor success. Rehabilitation Counseling Bulletin, 1971, 15, 58-67.

Wehr, M., \& Wittmer, J. Paraprofessional trainees and counselor education students: A comparison of personality and predicted counseling effectiveness. Counselor Education and Supervision, 1973, 12, 255-261.

Whiteley, J. M. Counselor education. Review of Educational Research, 1969, 39, 173-187.

Whiteley, J. M., Sprinthall, N. A., Mosher, R. L., \& Donagly, R. T. Selection and evaluation of counselor effectiveness. Journal of Counseling Psychology, 1967, 14, 226-234.

Wicas, E. A., \& Mahan, T. W., Jr. Characteristics of counselors rated effective by supervisors and peers. Counselor Education and Supervision, 1966, 6, 50-56.

Winborn, B. B. Systematic counseling: A model for accountability in counseling and counselor education. Impact, 1973, 2, 15-22.

Winborn, B. B., \& Rowe, W. Self-actualization and the communication of facilitative conditions: A replication. Journal of Counseling Psychology, 1972, 19, 26-29.

Wittmer, J., \& Lister, J. L. The Graduate Record Examination, 16PF Questionnaire, and counseling effectiveness. Counselor Education and Supervision, $1971,10,293$.

\section{AUTHORS}

ROWE, WAYNE Address: College of Education, University of Oklahoma, Norman, OK 73069. Title: Associate Professor of Education. Degrees: A.B., Western Michigan University; M.A., Ph.D., Michigan State University. Specialization: Systems analysis in counselor education.

MURPHY, HARRY B. Address: Counseling Center, University of Oklahoma, Norman, OK 73069. Title: Counselor.Degrees: B.A., M.A., University of Texas at El Paso.Specialization: Counselor education; analysis of interview process.

DE CSIPKES, ROBERT A. Address: Psychiatry Department, National Naval Medical Center, Bethesda, MD 20014. Title: Psychologist Intern. Degrees: B.A., Wagner College; M.A., Springfield (Mass.) College. Specialization: Counselor education outcome research. 